\title{
Reviewer Appreciation
}

\section{Kikuo Okuyama, Editor-in-Chief}

Hiroshima University, Japan

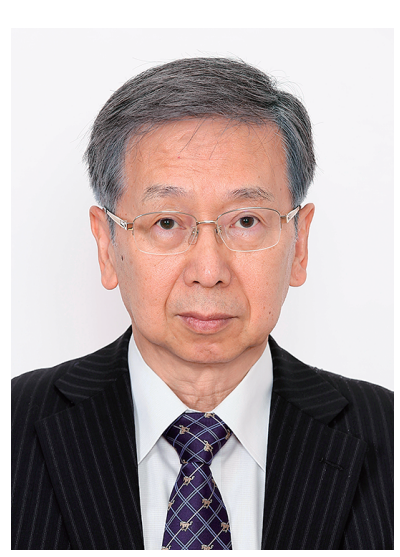

I would like to express my sincere gratitude to the reviewers for their hard work for the KONA Powder and Particle Journal. Thanks to the generous contributions of the volunteer reviewers as well as the interest of researchers in our journal, the number of submission to this journal is increasing after the registration on the major international journal platforms and its level is further improving. Because of the limited space of this annual journal, the number of papers published here is regrettably rather restricted. Therefore only the papers of good quality will be selected for the journal and further improved and refined by the reviewing process.

The editorial team of the KONA Journal would like to take this opportunity to gratefully acknowledge the reviewers here and deeply appreciate their valuable time and professional contributions to the KONA Journal. We apologize to any reviewers who may have been inadvertently omitted from this list. We are sincerely grateful to all who have been of any assistance to the publication of this journal.

\author{
BIRIS, Alexandru \\ BISCANS, Béatrice \\ BOURGEOIS, Florent \\ FUJIMOTO, Toshiyuki \\ FUKUI, Kunihiro \\ HICKEY, Anthony \\ HIGASHITANI, Ko \\ IIJIMA, Motoyuki
}

\author{
ISKANDAR, Ferry \\ KAGE, Hiroyuki \\ KUROSE, Ryoichi \\ LENGGORO, Wuled \\ MEESTERS, Gabriel \\ MILANI, Paolo \\ OGATA, Koichiro \\ OGI, Takashi
}

\author{
OKUYAMA, Kikuo \\ OTANI, Yoshio \\ PURI, Virendra \\ RASTEIRO, Maria da Graça \\ SAITO, Fumio \\ TSUJI, Takuya \\ WANG, Wei-Ning \\ YOKOYAMA, Toyokazu
}

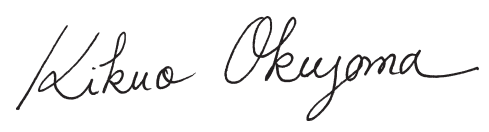

October 2018 